\title{
Relationship between thiamine and subacute ruminal acidosis induced by a high-grain diet in dairy cows
}

\author{
X. H. Pan, ${ }^{*} \dagger$ L. Yang, ${ }^{*}$ F. G. Xue, ${ }^{*}$ H. R. Xin, ${ }^{*}$ L. S. Jiang,‡ B. H. Xiong, ${ }^{, 1}$ and Y. Beckers $\dagger^{1}$ \\ *State Key Laboratory of Animal Nutrition, Institute of Animal Science, Chinese Academy of Agricultural Sciences, Beijing, 100193, P. R. China \\ †Animal Science Unit, Gembloux Agro-Bio Tech, University of Liège, Passage des Déportés 2, B-5030 Gembloux, Belgium \\ łBeijing Key Laboratory for Dairy Cow Nutrition, Beijing University of Agriculture, Beijing, 102206, P. R. China
}

\begin{abstract}
Two experiments were conducted to reveal the effects of grain-induced subacute rumen acidosis (SARA) on thiamine status in blood and rumen fluid in dairy cows. In both experiments, 6 multiparous, rumen-fistulated Holstein dairy cows were used in a 2-treatment, 2-period crossover design. Each experimental period consisted of $21 \mathrm{~d}$ (total of $42 \mathrm{~d}$ ). Experiment 1 was to investigate the effects of SARA on thiamine status in blood and rumen fluid. Treatments were either control (20\% starch, dry matter basis) or SARA-inducing diet (SAID, 33.2\% starch, dry matter basis). In experiment 2 , the effects of dietary thiamine supplementation on attenuating SARA and ruminal fermentation characteristics in dairy cows were studied. All cows received the same SAID diet during the whole experimental period; treatments were with or without thiamine (180 $\mathrm{mg}$ of thiamine $/ \mathrm{kg}$ of dry matter intake). In both experiments, rumen fluid samples were collected at $0,3,6$, 9 , and $12 \mathrm{~h}$ after morning feeding on $\mathrm{d} 21$ and 42 of the experiments for measurement of $\mathrm{pH}$, thiamine, volatile fatty acid, and lactate contents. Peripheral blood was also collected at $3 \mathrm{~h}$ after morning feeding on $\mathrm{d} 21$ and 42 to measure thiamine, carbohydrate metabolites, and enzyme activities. In experiment 1 , cows fed the SAID diet had lower ruminal and plasma thiamine concentrations and higher lactate than cows fed the control diet. The ruminal thiamine contents were positively related to $\mathrm{pH}$ and the concentrations of acetate in the rumen, and negatively correlated with the lactate contents. Experiment 2 demonstrated that ruminal $\mathrm{pH}$ and the concentrations of thiamine, acetate, and total volatile fatty acids in the rumen were increased, whereas ruminal lactate contents were reduced by thiamine supplementation. The concentrations of lactate and the activity of lactate dehydrogenase in blood were
\end{abstract}

\footnotetext{
Received January 6, 2016.

Accepted June 3, 2016.

${ }^{1}$ Corresponding authors: bhxiong@iascaas.net.cn and yves.beckers@ ulg.ac.be
}

reduced in the thiamine supplemented group, and the opposite was true for the nonesterified fatty acids and $\alpha$-ketoneglutarate dehydrogenase contents. In conclusion, the thiamine status was affected by SARA in dairy cows and ruminal infusion of thiamine could help attenuate SARA by improving the proportions of ruminal volatile fatty acids and reducing lactate contents in rumen fluid and blood.

Key words: dairy cow, rumen fermentation, subacute rumen acidosis, thiamine

\section{INTRODUCTION}

It is well established that thiamine is an essential cofactor required for carbohydrate metabolism and that ruminants have no dietary thiamine requirements because of the ability of the rumen microbes to synthesize ruminal thiamine (Breves et al., 1981; Miller et al., 1986). However, SARA caused by feeding diets high in readily fermentable carbohydrates is known to reduce the ruminal $\mathrm{pH}$ and microbial activity (Mao et al., 2016) and may therefore affect the amount of thiamine production. Although several studies have indicated that increasing nonfiber carbohydrates in the diet decreases the daily apparent synthesis of thiamine in the rumen (Schwab et al., 2006) or increases the duodenal flow of thiamine (Zinn et al., 1987), experimental data are limited on the effects of SARA on thiamine status when excess grain amounts are offered to dairy cows.

In addition, thiamine is the coenzyme of pyruvate dehydrogenase (PDH) and $\alpha$-ketoneglutaric acid dehydrogenase ( $\boldsymbol{\alpha}$-KGDHC) in carbohydrate metabolism (Bubber et al., 2004). Dairy cows in SARA caused by excess grain diets may have higher thiamine requirements than cows under common feeding conditions; the deficiency of thiamine would cause the accumulation of pyruvate, and then pyruvate is converted into lactate by lactate dehydrogenase (Kumar et al., 2015). Our previous research found some evidence that adding 180 $\mathrm{mg}$ of thiamine/ $\mathrm{kg}$ of DMI could increase the rumen $\mathrm{pH}$ and regulate the structure of rumen microbial community in vivo (Wang et al., 2015). Thus, we hypothesized 
that thiamine supplementation could attenuate SARA by promoting the flow of pyruvate to the TCA cycle and reducing the accumulation of lactate in the rumen. The objective of this study was to reveal the relationship between SARA and thiamine by investigating the effects of SARA on thiamine status and the effects of thiamine supplementation on SARA and carbohydrate metabolism.

\section{MATERIALS AND METHODS}

Two experiments were conducted to reveal the relationship between SARA and thiamine. Animal care and procedures were in accordance with the Chinese guidelines for animal welfare and approved by the Animal Care and Use Committee of the Chinese Academy of Agricultural Sciences.

\section{Animals and Experimental Design}

Experiment 1. Six Chinese Holstein dairy cows (610 $\pm 35.8 \mathrm{~kg}$ of BW; $62 \pm 7.4$ DIM) in second parity fitted with $10-\mathrm{cm}$ ruminal cannulas (Bar Diamond, Parma, ID) were used in this experiment. The experiment was run as a $2 \times 2$ (2 treatments, 2 periods) crossover design. Treatments were either a control diet (COD; $20 \%$ starch, DM basis) or a SARA-inducing diet (SAID; $33.2 \%$ starch, DM basis). Each experimental period consisted of $21 \mathrm{~d}$ (total of $42 \mathrm{~d}$ ).

Experiment 2. The SARA was induced in 6 multiparous Chinese Holstein cows $(635.7 \pm 46.4 \mathrm{~kg}$ of BW; $115 \pm 7.4$ DIM) from d -21 until d 0 by feeding a SAID (Table 1). Then cows were randomly assigned to 2 treatments (with or without thiamine) in a crossover design; each period lasted $21 \mathrm{~d}$ (total of $42 \mathrm{~d}$ ). The 180 $\mathrm{mg}$ of thiamine $/ \mathrm{kg}$ of DMI (thiamine hydrochloride, purity $\geq 99 \%$; Wanrong Science and Technology Development Co., Ltd., Wuhan, China) was administered via the rumen cannula twice daily after diets were supplied. This dose of thiamine was selected based on our previous dose-response studies $(0,60,120,180$, and 240 $\mathrm{mg}$ of thiamine $/ \mathrm{kg}$ of DMI) with dairy cows (Zhang et al., 2014; Wang et al., 2015), which demonstrated that $180 \mathrm{mg}$ of thiamine/ $\mathrm{kg}$ of DMI appeared to be better at stabilizing ruminal fermentation and balancing the population of lactic acid-producing and -consuming bacteria compared with the other doses.

\section{Experimental Diets and Feeding}

The diets were formulated according to NRC (2001) to meet or exceed the energy requirements of Holstein dairy cows yielding $20 \mathrm{~kg}$ of milk/d with $3.5 \%$ milk fat and $3.0 \%$ true protein. Diet composition and its chemical analysis are shown in Table 1. Experimental animals were fed a TMR ad libitum twice daily at 0600 and $1800 \mathrm{~h}$. Individual cow feed intake was recorded daily during the experimental period. The TMR samples and orts were collected daily, stored at $-20^{\circ} \mathrm{C}$, and pooled weekly for analyses. The DM was determined by oven drying at $105^{\circ} \mathrm{C}$ until a constant weight was obtained (method 930.15, AOAC International, 1995). The CP content was measured by a Kjeldahl nitrogen analysis (method 954.01, AOAC International, 1995). Ether extract was determined using a Soxhlet apparatus (method 945.16, AOAC International, 1995). Contents of NDF and ADF were determined according to the procedure of Van Soest et al. (1991) using heat-stable amylase (Sigma no. A3306, Sigma Chemical Co., St. Louis, MO) and sodium sulfite, and expressed without residual ash. The total ash content was determined using AOAC method 942.05 (AOAC, 1990). Dietary calcium and phosphorus contents were analyzed using colorimetric method according to the

Table 1. Ingredient and chemical composition of the experimental diets $^{1}$

\begin{tabular}{|c|c|c|}
\hline Item & COD & SAID \\
\hline \multicolumn{3}{|l|}{ Ingredient ( $\%$ of DM) } \\
\hline Chinese wildrye & 11.0 & 5.0 \\
\hline Corn silage & 34.0 & 15.0 \\
\hline Alfalfa hay & 15.0 & 15.0 \\
\hline Ground corn & 10.0 & 35.0 \\
\hline Soybean meal, $43 \%$ CP & 14.0 & 14.0 \\
\hline Cottonseed meal & 5.0 & 5.0 \\
\hline Distillers dried grains with solubles & 5.0 & 5.0 \\
\hline Whole cottonseed & 3.0 & 3.0 \\
\hline Limestone meal & 1.0 & 1.0 \\
\hline Calcium hydrogen phosphate & 0.7 & 0.7 \\
\hline Sodium chloride & 0.5 & 0.5 \\
\hline Premix $^{2}$ & 0.8 & 0.8 \\
\hline \multicolumn{3}{|l|}{$\begin{array}{l}\text { Nutrient composition (\% of DM, } \\
\text { unless otherwise indicated) }\end{array}$} \\
\hline $\mathrm{NE}_{\mathrm{L}}^{3}(\mathrm{Mcal} / \mathrm{kg})$ & 1.6 & 1.7 \\
\hline $\mathrm{CP}$ & 18.2 & 18.0 \\
\hline Starch & 20.0 & 33.2 \\
\hline $\mathrm{NDF}$ & 36.2 & 25.8 \\
\hline $\mathrm{ADF}$ & 23.4 & 17.7 \\
\hline $\mathrm{NFC}^{4}$ & 34.6 & 46.5 \\
\hline Ether extract & 4.6 & 4.1 \\
\hline Ash & 6.5 & 5.6 \\
\hline Calcium & 0.88 & 0.84 \\
\hline Phosphorus & 0.55 & 0.55 \\
\hline Thiamine $(\mathrm{mg} / \mathrm{kg})$ & 1.7 & 2.3 \\
\hline DMI $(\mathrm{kg} / \mathrm{d})$ & 18.6 & 22.5 \\
\hline Thiamine intake $(\mathrm{mg} / \mathrm{d})$ & 32.2 & 52.3 \\
\hline
\end{tabular}

${ }^{1} \mathrm{COD}=$ control diet; SAID = SARA-inducing diet.

${ }^{2}$ Premix contained (per kg): 2,142 $\mathrm{mg}$ of $\mathrm{Cu}$ (as sulfate); 15,428 $\mathrm{mg}$ of Mn (as sulfate); $15,428 \mathrm{mg}$ of Zn (as sulfate); $28 \mathrm{mg}$ of Co (as chloride); $231 \mathrm{mg}$ of I (as iodate); $57 \mathrm{mg}$ of Se (as selenite); 2,285,000 IU of vitamin A; 457,000 IU of vitamin D; 11,400 $\mathrm{mg}$ of vitamin $\mathrm{E}$.

${ }^{3} \mathrm{NE}_{\mathrm{L}}$ was estimated according to NRC (2001).

${ }^{4} \mathrm{NFC}=100-(\% \mathrm{NDF}+\% \mathrm{CP}+\%$ ether extract $+\%$ ash $)(\mathrm{NRC}$, 2001). 
Chinese National Standard GB/T 6436-2002 and GB/ T6437-2002, respectively. The starch in the sample was determined by an enzymatic method ( $\alpha$-amylase and amyloglucosidase) using a commercial starch analysis kit (Megazyme, International Ireland Ltd., Bray, Ireland). The thiamine in feeds was extracted according to the Chinese National Standard (GB/T 14700-2002; Analytical Methods Committee, 2000) and determined by a commercial ELISA kit (TSZ Biological Trade Co., Ltd., Boston, MA).

\section{Induction of SARA}

For the SAID group, the concentrate level was gradually increased at a rate of $5 \%$ per day during the first 4 d. This period was followed by a 12 -d adaptation period to the diet and then by $5 \mathrm{~d}$ of sampling. From d 17 until d 20, ruminal fluid samples were collected and $\mathrm{pH}$ was determined every $1.5 \mathrm{~h}$ from 0 to $12 \mathrm{~h}$ postfeeding. The threshold $\mathrm{pH}<5.8$ was adopted (Penner et al., 2007) and SARA was considered to be induced if the duration below pH 5.8 was $\geq 3 \mathrm{~h} / \mathrm{d}$ (Khafipour et al., 2009).

\section{Ruminal Fluid Sampling and Analysis}

Rumen contents were sampled from cranial, caudal, dorsal, and ventral aspects of the rumen at $0,3,6,9$, and $12 \mathrm{~h}$ after the morning feeding on $\mathrm{d} 21$ of each experimental period. Rumen contents were strained through 4 layers of cheesecloth with a mesh size of $250 \mu \mathrm{m}$. Ruminal $\mathrm{pH}$ was measured immediately using a portable type $\mathrm{pH}$ meter (Testo 205, Testo AG, Lenzkirch, Germany). The filtered rumen fluid samples were centrifuged at $10,000 \times g$ for $15 \mathrm{~min}$ at $4^{\circ} \mathrm{C}$. Five milliliters of clear supernatant samples was transferred into tubes and stored at $-20^{\circ} \mathrm{C}$ for analysis of thiamine. Another $10 \mathrm{~mL}$ of clear supernatant samples was mixed with $2 \mathrm{~mL}$ of $250 \mathrm{~g} / \mathrm{L}$ of metaphosphoric acid and stored at $-20^{\circ} \mathrm{C}$ for VFA and lactate determination.

The lactate concentrations in rumen fluid were measured using enzymatic methods by commercial kits (A019-2, Nanjing Jiancheng Bioengineering Institute, Nanjing, China; technical parameters: recovery rate, 99\%; CV, $1.7 \%$; sensitivity $<0.1 \mathrm{mmol} / \mathrm{L}$; detection range, $0-6 \mathrm{mmol} / \mathrm{L}$ ) at $530 \mathrm{~nm}$ according to the manufacturer's instructions (Jia et al., 2012). Individual and total VFA (TVFA) in aliquots of ruminal fluid were determined by gas chromatograph (GC-2010, Shimadzu, Kyoto, Japan; Hu et al., 2005). The concentrations of thiamine in rumen fluid were determined by a commercially available bovine thiamine ELISA kit (TSZ Biological Trade Co., Ltd., Boston, MA) according to the manufacturer's instructions. All samples including the standards were tested induplicate, and the optical density values were read at $450 \mathrm{~nm}$ by a microplate reader (Multiskan MK3, Thermo Labsystems, Beverly, MA).

\section{Blood Sampling and Analysis}

Approximately $3 \mathrm{~h}$ after morning feeding on $\mathrm{d} 21$ of each period, coccygeal blood samples were taken and collected into $10-\mathrm{mL}$ evacuated tubes coated with freeze-dried sodium heparin (Kindly Enterprise Development Group Co., Ltd., Shanghai, China). Samples were immediately kept on ice until being centrifuged at $3,000 \times g$ for $15 \mathrm{~min}$ at $4^{\circ} \mathrm{C}$ to harvest plasma. The plasma was divided into $2-\mathrm{mL}$ aliquots and stored at $-20^{\circ} \mathrm{C}$ for further analysis.

Plasma concentrations of lactate and thiamine were determined using kits mentioned above. Pyruvate (colorimetric method; A081), BHB (enzymatic colorimetric method; E30-01), nonesterified fatty acids (NEFA; enzymatic method; A042-2), and the activity of lactate dehydrogenase (colorimetric method; A020-2) in the plasma were determined by commercially kits (Nanjing Jiancheng Bioengineering Institute, Nanjing, China). The activity of PDH (EC 1.2.4.1) and $\alpha$-KGDHC (EC 1.2.4.2) was analyzed using the ELISA method and absorbance was read with a Multiskan MK3 microplate reader (Thermo Labsystems) at $450 \mathrm{~nm}$, which was adapted from Yamane et al. (2014). The antibody of bovine ELISA kits used in our study were purchased from Abcam (Cambridge, MA) and then sub-packaged by DG Biotech (Beijing, China). The technical parameters of PDH-ELISA kits are as follows: sensitivity $<0.1 \mathrm{IU} / \mathrm{L}$; recovery rate, $99 \%$; detection range, 0 to 8 IU/L. For $\alpha-K G D H C$ activity determination kits, the technical parameters are as follows: sensitivity $<1.0$ $\mu \mathrm{g} / \mathrm{mL}$; recovery rate, $99 \%$; and detection range, 0 to $48 \mu \mathrm{g} / \mathrm{mL}$.

\section{Statistical Analysis}

Shapiro-Wilk and Levene tests were used to test for normality and homogeneity of variances, respectively. Ruminal acetate, propionate, isobutyrate, valerate, total VFA, and lactate in experiment 2 were abnormal based on the Shapiro-Wilk test. The raw data of acetate and total VFA were transformed by logarithmic transformations; propionate, isobutyrate, valerate, and lactate parameters were transformed by square root transformations. Homogeneity test showed that data were homogeneous.

Differences between treatments were analyzed using the MIXED procedure of SAS 9.3 (SAS Institute Inc., Cary, NC) according to a crossover design. The following model was fitted for ruminal variables (ruminal $\mathrm{pH}$, 


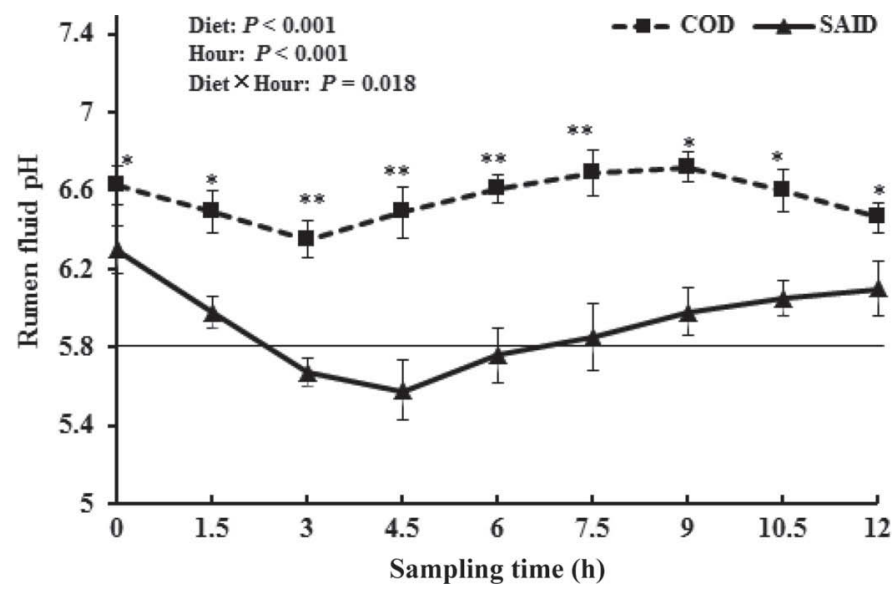

Figure 1. Mean ruminal $\mathrm{pH}$ values for cows fed the control diet (COD) and SARA cows fed the SARA-inducing diet (SAID). Data were expressed as mean $\pm \mathrm{SE} . *$ indicates differences between dietary treatments at $P \leq 0.05{ }^{* *}$ indicates differences between dietary treatments at $P \leq 0.01$.

thiamine, lactate and VFA) with repeated measures over time:

$$
\begin{aligned}
Y_{i j k l m}=\mu & +S_{i}+C_{j}\left(S_{i}\right)+T_{k}+P_{l}+H_{m}+T_{k} \\
& \times P_{l}+T_{k} \times H_{m}+e_{i j k l m},
\end{aligned}
$$

where $Y_{i j k l m}$ is the dependent variable, $\mu$ is the overall mean, $S_{i}$ is the random effect of sequence $(i=1-2)$; $C_{j}\left(S_{i}\right)$ is the random effect of cow nested in sequence $(j=1-6) ; T_{k}$ is the fixed effect of treatment $(k=1-2)$, $P_{l}$ is the fixed effect of period $l(l=1-2) ; H_{m}$ is the fixed effect of sampling hour $(m=1-5) ; T_{k} \times P_{l}$ is the fixed effect of the treatment by period interaction; $T_{k} \times H_{m}$ is the fixed effect of the treatment by time interaction, and $e_{i j k l m}$ is the random residual error. The measurements obtained from the same cow at a different sampling hour were treated as a repeated measure.

Blood variables (thiamine, pyruvate, lactate, BHB, NEFA, lactate dehydrogenase, PDH, $\alpha-K G D H C)$ with no repeated measures were analyzed according to the following statistical model (Goiri et al., 2010):

$$
Y_{i j k l}=\mu+S_{i}+C_{j}\left(S_{i}\right)+T_{k}+P_{l}+T_{k} \times P_{l}+e_{i j k l},
$$

where $Y_{i j k l}$ is the dependent variable, $\mu$ is the overall mean, $S_{i}$ is the random effect of sequence $(i=1-2)$; $C_{j}\left(S_{i}\right)$ is the random effect of cow nested in sequence $(j=1-6) ; T_{k}$ is the fixed effect of treatment $(k=1-2)$; $P_{l}$ is the fixed effect of period $l(l=1-2) ; T_{k} \times P_{l}$ is the fixed effect of the treatment by period interaction; $e_{i j k l}$ is the random residual error. The sequence, experimental period, and interaction between treatment and period had no effect on any of the variables in this study and are not presented in the tables and figures.

Regressions among ruminal thiamine and $\mathrm{pH}$, lactate, and VFA were performed on 60 pieces of data [6 animals $\times 5$ sampling times $(0,3,6,9,12 \mathrm{~h}) \times$ 2 diets, $\mathrm{n}=60$ ]; relationships between thiamine and lactate in blood were analyzed on 12 pieces of data $[6$ animals $\times 1$ sampling time $(3 \mathrm{~h}$ after morning feeding) $\times 2$ diets, $\mathrm{n}=12$ ]. The independence of observations was tested using Durbin-Watson statistic before regression; we found that autocorrelations existed with $\mathrm{pH}$, lactate, acetate, propionate, and TVFA as independent variables. Data were transformed using generalized least squares method (GLS) to eliminate autocorrelation, and relationships were assessed based on transformed data using PROC REG of SAS 9.3. The standard error of the mean, $P$-value, and $\mathrm{R}^{2}$ were used to evaluate the correlations. Significance was declared at $P \leq 0.05$, a tendency was considered at $0.05<P<$ 0.10 in this study.

\section{RESULTS}

\section{Ruminal pH, Thiamine, VFA, and Lactate Concentrations}

The rumen data at 2 different concentrate levels are presented in Figure 1 and Table 2. Ruminal $\mathrm{pH}$ in cows fed the SAID diet was lower than COD group from 0 to $12 \mathrm{~h}$ after morning feeding $(P<0.05)$, and $\mathrm{pH}$ was below 5.8 for more than $3 \mathrm{~h} / \mathrm{d}$ (Figure 1). Concentrations of ruminal thiamine $(P<0.001)$ and acetate $(P$ $<0.001)$ were significantly decreased in SAID cows compared with COD. Lactate $(P<0.001)$, propionate $(P=0.042)$, isobutyrate $(P<0.001)$, and butyrate $(P$ $=0.021)$ were higher in the SAID group.

The high-grain feeding tended to increase ruminal pyruvate $(P=0.088)$ and decrease the activity of $\mathrm{PDH}$ $(P=0.094)$. The concentrations of isovalerate $(P=$ $0.35)$, valerate $(P=0.32)$, and TVFA $(P=0.66)$ did not differ between the 2 groups. The ruminal $\mathrm{pH}$ and concentrations of thiamine, lactate, and VFA were affected by the sampling time point $(P<0.05)$, and by the interaction between diet and sampling time $(P<$ $0.05)$, except for isovalerate $(P=0.051)$.

\section{Plasma Thiamine, Metabolites, and Enzyme Activity}

The concentrations of thiamine, metabolites and enzymes activity in peripheral blood of dairy cows are shown in Table 3. The concentrations of plasma thiamine $(P<0.001)$ and $\alpha-\mathrm{KGDHC}$ activity $(P=$ 
PAN ET AL.

Table 2. Effects of different diets on thiamine status and metabolites in the rumen of dairy cows

\begin{tabular}{|c|c|c|c|c|c|c|}
\hline \multirow[b]{2}{*}{ Item } & \multicolumn{2}{|c|}{ Treatment $^{1}$} & \multirow[b]{2}{*}{ SEM } & \multicolumn{3}{|c|}{$P$-value } \\
\hline & COD & SAID & & Diet & Hour $^{2}$ & Diet $\times$ hour \\
\hline Thiamine $(\mu \mathrm{g} / \mathrm{L})$ & 7.88 & 2.97 & 0.27 & $<0.001$ & $<0.001$ & 0.003 \\
\hline $\mathrm{pH}$ & 6.55 & 5.98 & 0.05 & $<0.001$ & $<0.001$ & 0.015 \\
\hline Lactate $(\mathrm{mmol} / \mathrm{L})$ & 0.61 & 1.43 & 0.057 & $<0.001$ & $<0.001$ & $<0.001$ \\
\hline Acetate $(\mathrm{mmol} / \mathrm{L})$ & 60.31 & 55.66 & 1.01 & $<0.001$ & $<0.001$ & $<0.001$ \\
\hline Propionate (mmol/L) & 17.57 & 19.67 & 0.61 & 0.042 & 0.007 & $<0.001$ \\
\hline Isobutyrate $(\mathrm{mmol} / \mathrm{L})$ & 1.10 & 1.34 & 0.05 & $<0.001$ & $<0.001$ & $<0.001$ \\
\hline Butyrate $(\mathrm{mmol} / \mathrm{L})$ & 10.20 & 10.93 & 0.31 & 0.021 & 0.004 & $<0.001$ \\
\hline Isovalerate $(\mathrm{mmol} / \mathrm{L})$ & 1.78 & 1.85 & 0.09 & 0.35 & $<0.001$ & 0.051 \\
\hline Valerate $(\mathrm{mmol} / \mathrm{L})$ & 1.20 & 1.26 & 0.06 & 0.32 & 0.033 & $<0.001$ \\
\hline $\mathrm{TVFA}^{3}(\mathrm{mmol} / \mathrm{L})$ & 92.16 & 90.71 & 1.94 & 0.66 & $<0.001$ & $<0.001$ \\
\hline Pyruvate $(\mathrm{mmol} / \mathrm{L})$ & 0.27 & 0.31 & 0.046 & 0.088 & 0.16 & 0.39 \\
\hline $\mathrm{PDH}^{4}(\mathrm{IU} / \mathrm{L})$ & 4.05 & 3.41 & 0.33 & 0.094 & 0.061 & 0.083 \\
\hline
\end{tabular}

0.007) in SAID cows were significantly lower than that in COD cows. The SAID cows had higher a level of lactate $(P=0.030)$ and lactate dehydrogenase $(P=$ $0.020)$ in plasma.

\section{Relationships Between VFA, Lactate, and Thiamine}

The relationships between $\mathrm{pH}$, acetate, propionate, TVFA, lactate, and thiamine concentrations in the rumen are presented in Table 4 . The thiamine concentrations in the rumen correlated positively with the ruminal $\mathrm{pH}\left(\mathrm{R}^{2}=0.51, P<0.001\right)$ and acetate $\left(\mathrm{R}^{2}=\right.$ $0.31, P<0.001)$. Negative relationships were observed between the concentrations of lactate and thiamine in the rumen $\left(\mathrm{R}^{2}=0.46, P<0.001\right)$. Ruminal thiamine had no significant linear relationships with the concentrations of propionate and TVFA in the rumen $(P>$ 0.05; Table 4).

The linear and negative relationships of thiamine concentrations to lactate were found in the blood (Fig- ure $2, \mathrm{R}^{2}=0.55, P=0.019$ ), which is consistent with their relationship in the rumen.

\section{Effects of Thiamine Supplementation on Rumen Fermentation and Blood Variables}

As shown in Figure 3, compared with cows with SARA, the infusion of $180 \mathrm{mg}$ of thiamine $/ \mathrm{kg}$ of DMI to the rumen increased the ruminal $\mathrm{pH}(P=0.027$; Figure 3B) and concentrations of ruminal thiamine $(P<0.001$; Figure 3A), acetate $(P<0.001$; Figure $3 \mathrm{D})$, and TVFA $(P=0.047$; Figure $3 \mathrm{~J})$. This infusion reduced lactate in rumen fluid significantly compared with the control $(P<0.001$; Figure 3C). No significant effects of thiamine supplementation $(P>0.05)$ on the concentrations of propionate, isobutyrate, butyrate, isovalerate, and valerate in the rumen were observed. The ruminal $\mathrm{pH}$ and the concentrations of thiamine, lactate, and VFA in rumen fluid were affected by the sampling time point $(P<0.05)$, and by the interaction

Table 3. Effects of different diets on the concentrations of thiamine, metabolites, and enzyme activity in peripheral blood of dairy cows ${ }^{1}$

\begin{tabular}{lrrcc}
\hline Item & COD & SAID & SEM & $P$-value \\
\hline Thiamine $(\mu \mathrm{g} / \mathrm{L})$ & 17.87 & 13.27 & 0.47 & $<0.001$ \\
Pyruvate $(\mathrm{mmol} / \mathrm{L})$ & 0.20 & 0.22 & 0.014 & 0.59 \\
Lactate $(\mathrm{mmol} / \mathrm{L})$ & 1.18 & 1.55 & 0.14 & 0.03 \\
BHB $(\mathrm{mmol} / \mathrm{L})$ & 0.80 & 0.78 & 0.12 & 0.89 \\
NEFA $(\mathrm{mmol} / \mathrm{L})$ & 70.02 & 65.09 & 4.28 & 0.28 \\
Lactate dehydrogenase $(\mathrm{U} / \mathrm{L})$ & 5,585 & 6,236 & 225.45 & 0.02 \\
PDH $(\mathrm{IU} / \mathrm{L})$ & 1.13 & 0.85 & 0.14 & 0.086 \\
$\alpha-K G D H C(\mathrm{mg} / \mathrm{L})$ & 18.67 & 16.49 & 0.61 & 0.007 \\
\hline
\end{tabular}

${ }^{1} \mathrm{COD}=$ control diet; SAID $=$ SARA-inducing diet; NEFA = nonesterified fatty acids; $\mathrm{PDH}=$ pyruvate dehydrogenase; $\alpha$-KGDHC $=\alpha$-ketoneglutarate dehydrogenase. 
Table 4. Linear regression of thiamine concentrations $(\mathrm{Y}, \mu \mathrm{g} / \mathrm{L}$ ) and $\mathrm{pH}$, lactate, and VFA (X-variables, $\mathrm{mmol} / \mathrm{L})$ in the rumen $(\mathrm{n}=60)$

\begin{tabular}{lrrrcc}
\hline X-variable & Slope & Intercept & $\mathrm{R}^{2}$ & $\mathrm{SE}$ & $P$-value \\
\hline $\mathrm{pH}$ & 4.17 & -20.50 & 0.33 & 2.39 & $<0.001$ \\
Lactate & -3.77 & 9.30 & 0.53 & 1.96 & $<0.001$ \\
Acetate & 0.22 & -7.15 & 0.38 & 2.29 & $<0.001$ \\
Propionate $_{\text {TVFA }^{1}}$ & -0.026 & 6.11 & 0.001 & 2.91 & 0.84 \\
\hline
\end{tabular}

${ }^{1}$ TVFA $=$ total volatile fatty acids.

between thiamine and sampling time $[P<0.05$, except for $\mathrm{pH}(P=0.19)$ and isobutyrate $(P=0.10)]$.

The effect of thiamine infusion on blood variables are presented in Table 5. Thiamine decreased the concentrations of plasma lactate $(P=0.045)$ and activity of lactate dehydrogenase $(P=0.035)$, and increased NEFA $(P=0.008)$ and $\alpha-K G D H C$ contents $(P=0.030)$ in blood. Thiamine supplementation tended to increase the concentrations of plasma thiamine $(P=0.066)$ and the activity of $\mathrm{PDH}(P=0.086)$. The plasma thiamine, pyruvate, BHB, and NEFA were not affected by thiamine supplementation $(P>0.05)$.

\section{DISCUSSION}

\section{Effects of SARA on Thiamine Status}

In the present study, the concentrations of thiamine in rumen fluid and blood of SARA cows were lower than those of COD cows, although SARA cows had higher thiamine intake (52.29 vs. $32.23 \mathrm{mg} / \mathrm{d}$, Table 1$)$. These results were in alignment with the results of Miller et al. (1986), who found that steers fed a high-grain diet (90\% corn) had lower ruminal thiamine concentrations than steers fed a diet with $30 \%$ corn, although thiamine content in concentrate feed was higher. The results above further confirmed the assumption that ruminal thiamine concentration was more closely related to the grain level than to the thiamine intake from the diet (Tafaj et al., 2006). The assumption can be explained by that the ruminal microbial thiamine synthesis depended on the intake of energy and digestible OM but not on the dietary thiamine intake (Steinberg and Kaufmann, 1977).

One criterion of thiamine deficiency is an increase in lactate and pyruvate concentrations in the blood (Dabak and Gul, 2004), and blood thiamine levels below $50 \mathrm{nmol} / \mathrm{L}(13.27 \mu \mathrm{g} / \mathrm{L})$ are considered indicative of deficiency (Hill et al., 1988). The thiamine pyrophosphate effect in the transketolase test is another method in the diagnosis of thiamine deficiency; increased thiamine pyrophosphate effect values of more than $45 \%$ implicate thiamine deficiency (Karapinar et al., 2008). Cows with SARA in our study had higher lactate and lactate dehydrogenase activity, and lower thiamine concentrations $(13.27$ and $12.53 \mu \mathrm{g} / \mathrm{L}$ in experiments 1 and 2 , respectively) and $\alpha$-KGDHC activity in blood, which proved that thiamine deficiency occurred when SARA was induced. Dabak and Gul (2004), Karapinar et al. (2008), and Karapinar et al. (2010) also proved that thiamine deficiency occurred when sheep had subacute or acute ruminal acidosis. Silverman and Werkman (1939) reported that certain propionateproducing bacteria make thiamine or its intermediates. Megasphaera elsdenii and Selenomonas ruminantium are the predominant propionate-producing organisms (Nagaraja and Lechtenberg, 2007), and thus the disappearance of $M$. elsdenii and S. ruminantium caused by high-grain feeding (Hernández et al., 2014) may affect the synthesis of thiamine or its intermediates. The decreased daily thiamine apparent synthesis under high NFC feeding has been proved by Schwab et al. (2006).

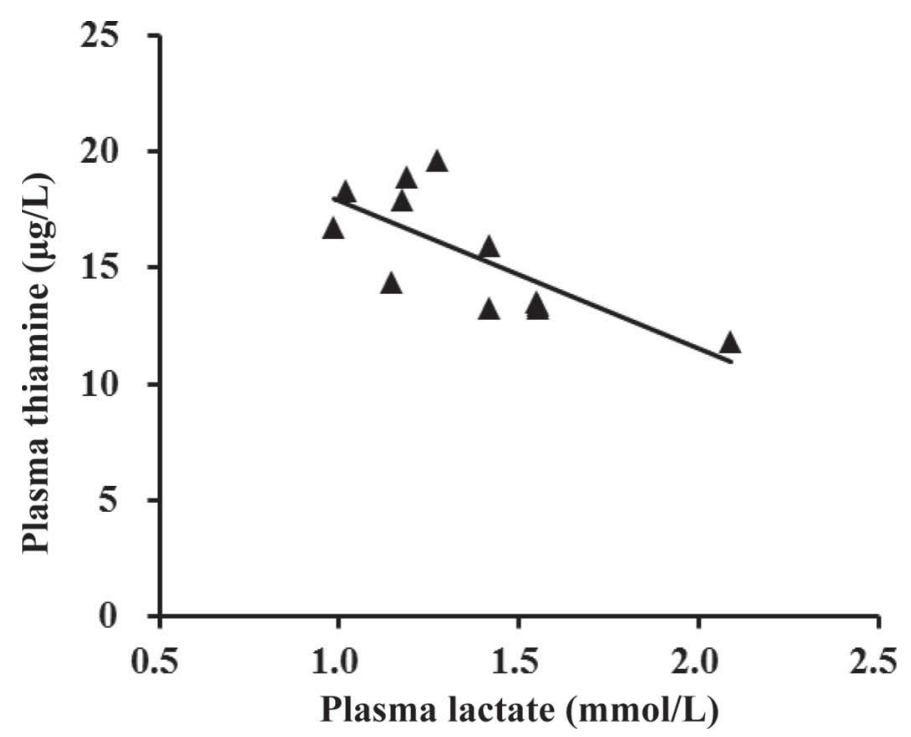

Figure 2. Linear regression of thiamine concentrations $(\mathrm{Y})$ and lactate $(\mathrm{X})$ in plasma. $\mathrm{Y}=-6.42 \mathrm{X}+24.34\left(\mathrm{R}^{2}=0.55, \mathrm{SE}=1.89, P\right.$ $=0.019, \mathrm{n}=12)$. 


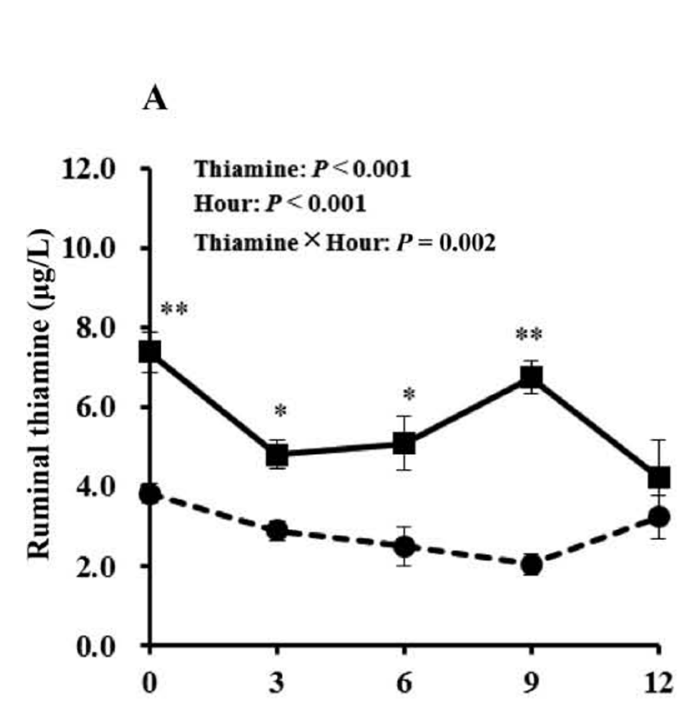

$\mathbf{B}$

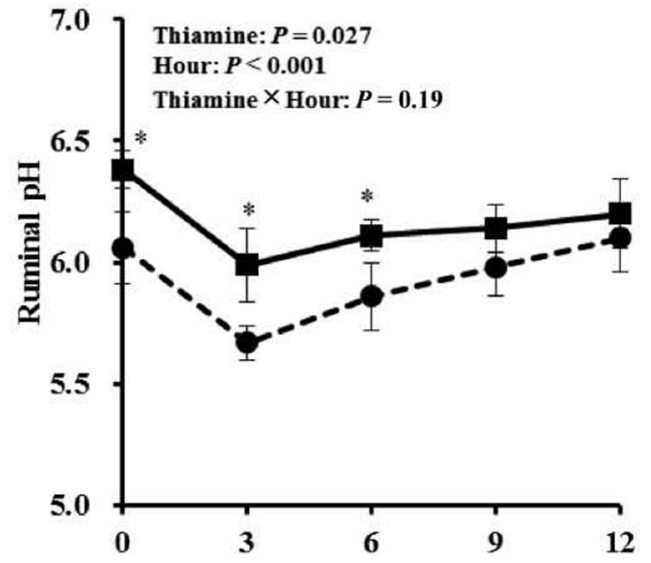

C

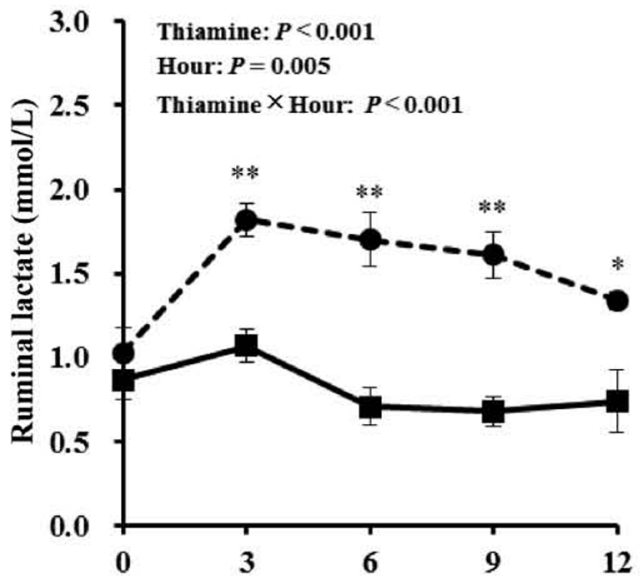

$\mathbf{E}$

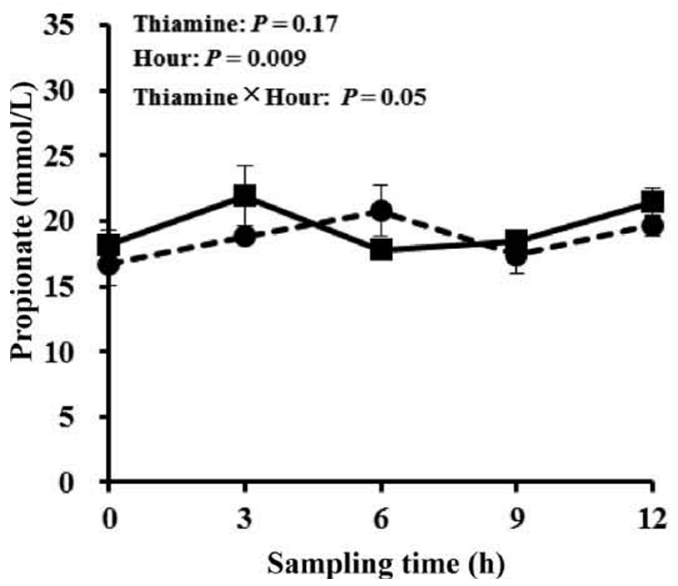

D

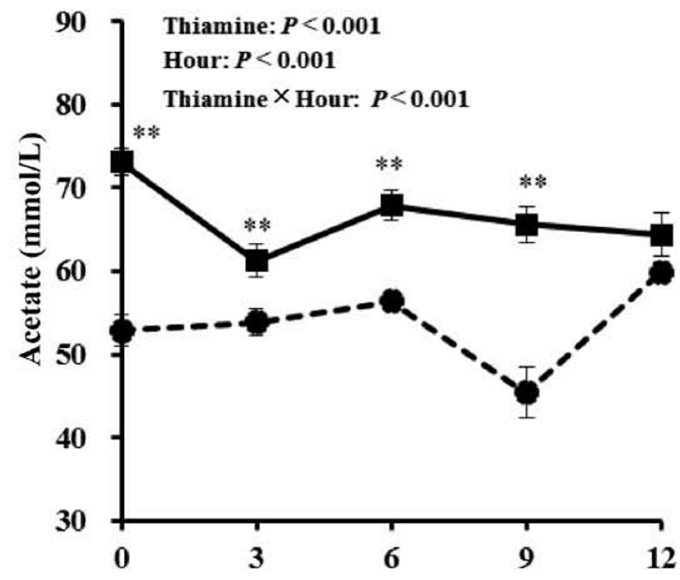

F

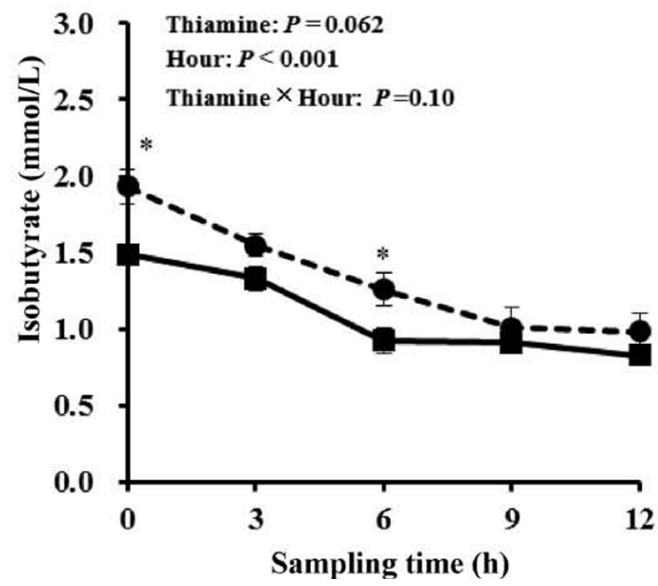

Figure 3. Effects of thiamine supplementation on ruminal pH, concentrations of thiamine, lactate, acetate, propionate, isobutyrate, butyrate, isovalerate, valerate, and total VFA (TVFA) in the rumen fluid of dairy cows. SARA represents SARA cows without thiamine supplement; SARA + T represents SARA cows supplemented with thiamine. Data are presented as means $\pm \mathrm{SE}$. * indicates differences between treatments at $P \leq 0.05 ; * *$ indicates differences between treatments at $P \leq 0.01$. 
G

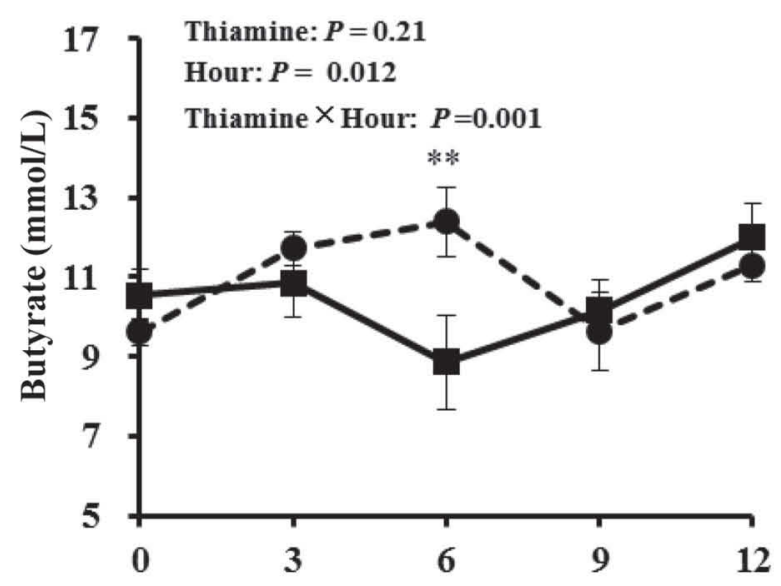

I

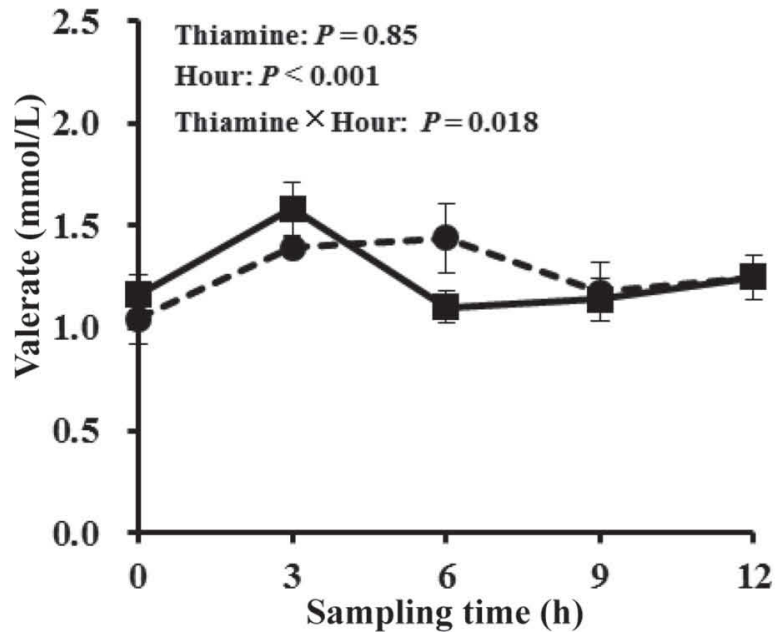

$\mathbf{H}$
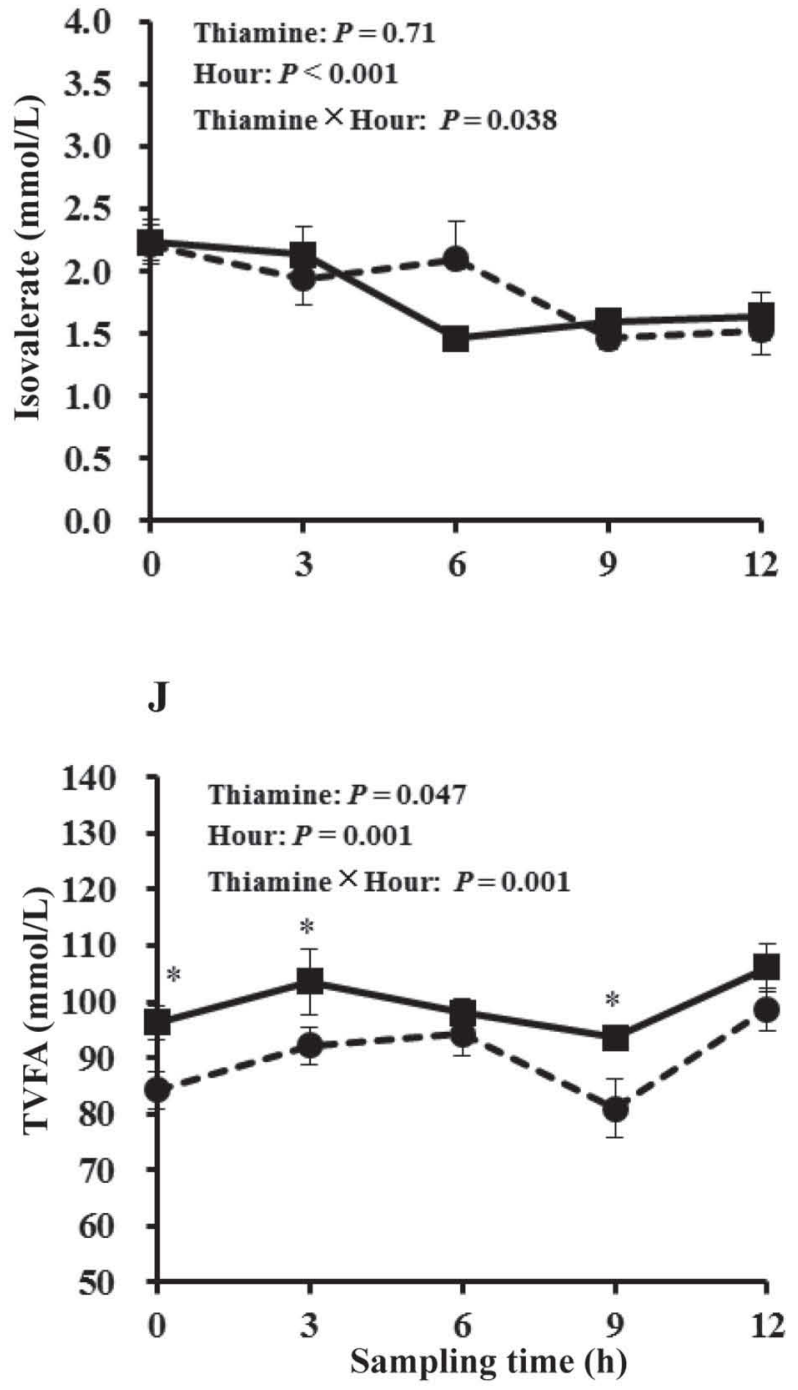

Figure 3 (Continued). Effects of thiamine supplementation on ruminal pH, concentrations of thiamine, lactate, acetate, propionate, isobutyrate, butyrate, isovalerate, valerate, and total VFA (TVFA) in the rumen fluid of dairy cows. SARA represents SARA cows without thiamine supplement; SARA + T represents SARA cows supplemented with thiamine. Data are presented as means \pm SE. * indicates differences between treatments at $P \leq 0.05$; ${ }^{*}$ indicates differences between treatments at $P \leq 0.01$.

Besides, a decrease in ruminal $\mathrm{pH}$ caused by high-grain diets was thought to increase thiaminase production (Brent, 1976). Clostridium sporogenes and a few species of Bacillus are the main culprits of ruminal thiaminase (Brent and Bartley, 1984); these species have optimum $\mathrm{pH}$ of 5.2 and 5.6, respectively (Boyd and Walton, 1977). The growth of Clostridium sporogenes and Bascillus was promoted when SARA (ruminal $\mathrm{pH}$ below 5.8) induced by high-grain feeding, resulting in an increase of thiaminase and thereby the increasing amount of thiamine degraded by thiaminase (Randhawa et al., 1988; Dunlop, 1998). In addition, thiamine is an important co-factor required for multiple enzymes (PDH, $\alpha$-KGDHC, and transketolase) involved in carbohydrate metabolism; therefore, more thiamine was required to meet the requirement of increasing carbohydrate metabolism when cows were fed a high-grain diet (Edwin and Jackman, 1970). Moreover, the low ruminal $\mathrm{pH}$ may impair gastrointestinal absorption of thiamine (Said et al., 1999). 


\section{Relationship Between $\mathrm{pH}$ and Thiamine Concentrations}

The positive relationship of thiamine concentrations to $\mathrm{pH}$ in our study was expected. It is well established that ruminal $\mathrm{pH}$ would be depressed by increasing grain levels (Krause and Oetzel, 2005; Li et al., 2012). In another study, we investigated the variation of thiaminase activity during SARA induction by increasing the proportion of dietary concentrate gradually. We founded that the activity of thiaminase increased significantly from $3.78 \mathrm{U} / \mathrm{mL}(50 \%$ concentrate) to $4.55 \mathrm{U} / \mathrm{mL}(60 \%$ concentrate), $5.42 \mathrm{U} / \mathrm{mL}$ ( $70 \%$ concentrate), and 10.33 $\mathrm{U} / \mathrm{mL}$ (80\% concentrate; X. H. Pan, unpublished data). The decrease in ruminal $\mathrm{pH}$ caused by high-grain levels promoted the growth of thiaminase-producing bacteria (e.g., Clostridium sporogenes and Bacillus), resulting in an increase of thiaminase production and thereby the increasing amount of thiamine degradation (Miller et al., 1986; Dunlop, 1998). In addition, the rising duodenal flow of thiamine along with high dietary grain leads to lower ruminal thiamine concentrations (Zinn et al., 1987). Moreover, as discussed above, daily thiamine apparent synthesis decreased when cows were fed highNFC diets (Schwab et al., 2006). The decrease in both ruminal $\mathrm{pH}$ and thiamine content leads to their positive relationship.

\section{Relationship Between VFA and Thiamine Concentrations}

In the rumen, dietary carbohydrates are usually converted to pyruvate and acetyl-CoA by microorganisms using the glycolytic pathway and pentose phosphate pathway (Macfarlane and Macfarlane, 2003), and finally pyruvates are mainly metabolized to lactate, VFA, and a small amount of carbon dioxide and methane (Friggens et al., 1998). The principal metabolic routes of pyruvate to predominant VFA according to the KEGG pathway (map 00620; Kanehisa and Goto,
2000) are as follows: (1) pyruvate can be reduced by NADH to produce lactate, and then lactate could convert to propionate via acrylate pathway; (2) pyruvates are converted to propionate by a reverse citric acid cycle known as the succinate-propionate pathway; (3) pyruvate can be degraded into acetyl-CoA, and then acetyl-CoA can be used for acetate and butyrate synthesis.

In our study, the acetate concentrations showed a high positive correlation to the thiamine concentrations in the rumen. Acetate mainly comes from the degradation of structural carbohydrates via the decarboxylation of pyruvate (Baldwin et al., 1963). Ruminococcus albus, Fibrobacter succinogenes, and Ruminococcus flavefaciens are the main acetate-producing bacteria and thiamine is indispensable during the growth of some strains of R. albus (Bryant and Robinson, 1961). As discussed above, ruminal thiamine contents decreased when SARA occurred, and the decreasing thiamine contents may impair the growth of some $R$. albus, resulting in a decrease in ruminal acetate. Thiamine supplementation increased the ruminal acetate in experiment 2 possibly due to its promoting effects on the growth of $R$. albus (Bryant and Robinson, 1961).

Propionate is formed from pyruvate in the rumen by the succinate or acrylate pathways mentioned above. The succinate pathway accounts for 70 to $100 \%$ of the propionate produced in the rumen (Baldwin et al., 1963). In our study, the high proportion of corn in SARA diet was rapidly fermented and converted into large amounts of pyruvate. The thiamine-dependent decarboxylation of pyruvate would be blocked by the increasing ruminal pyruvate but decreasing PDH activity when cows were fed a high-grain diet; hence, the flow of pyruvate to succinate or lactate was enhanced and thereby ruminal propionate contents increased in the present study. The facts above indicated that the increasing ruminal propionate concentrations caused by high grain feeding may be partially associated with the decreasing thiamine concentrations in the rumen.

Table 5. Effects of thiamine supplementation on blood variables

\begin{tabular}{lcccc}
\hline Item & SARA & SARA + thiamine & SEM & $P$-value \\
\hline Thiamine $(\mu \mathrm{g} / \mathrm{L})$ & 12.53 & 14.59 & 0.63 & 0.066 \\
Pyruvate $(\mathrm{mmol} / \mathrm{L})$ & 0.19 & 0.19 & 0.014 & 0.84 \\
Lactate $(\mathrm{mmol} / \mathrm{L})$ & 1.55 & 1.03 & 0.18 & 0.045 \\
$\mathrm{BHB}(\mathrm{mmol} / \mathrm{L})$ & 0.78 & 0.91 & 0.14 & 0.41 \\
$\mathrm{NEFA}^{1}(\mathrm{mmol} / \mathrm{L})$ & 66.13 & 82.56 & 2.56 & 0.008 \\
$\mathrm{Lactate}^{2}$ dehydrogenase $(\mathrm{U} / \mathrm{L})$ & 6,229 & 4,973 & 400.89 & 0.035 \\
$\mathrm{PDH}^{2}(\mathrm{IU} / \mathrm{L})$ & 0.85 & 1.02 & 0.12 & 0.22 \\
$\alpha-\mathrm{KGDHC}(\mathrm{mg} / \mathrm{L})$ & 16.49 & 21.33 & 1.47 & 0.03 \\
${ }^{1} \mathrm{NEFA}=$ nonesterified fatty acids. & & & & \\
${ }^{2} \mathrm{PDH}=$ pyruvate dehydrogenase. & & & & \\
${ }^{3} \alpha-\mathrm{KGDHC}=\alpha$-ketoneglutarate dehydrogenase. & & & &
\end{tabular}


However, no significant relationship was found between the concentrations of propionate and thiamine in the rumen. The nonsignificant relationship may be explained in that propionate production is not solely determined by thiamine status, but determined largely by the contents of its substrate, namely by the dietary carbohydrate contents (Macfarlane and Macfarlane, 2003) and fermentability (Yahaghi et al., 2012).

The total VFA had no significant relationship with ruminal thiamine, and the concentrations of TVFA in SARA cows were lower compared with Gozho et al. (2007), Li et al. (2012), and Schlau et al. (2012). The one possible reason was that SARA was induced by different grain sources. Acid production in the rumen is primarily due to fermentation of carbohydrates, and affected by substrate composition, substrate availability, and rate of depolymerization. In the studies of Gozho et al. (2007), Li et al. (2012), and Schlau et al. (2012), SARA was induced by high proportions of wheat, barley, or oats in the diet, whereas SARA was induced by high dietary corn in our study. Oats, wheat, and barley have higher degradability of starch and higher ruminal availability than corn (Herrera-Saldana et al., 1990). Besides, animal factors may affect ruminal VFA concentrations. O'Grady et al. (2008) investigated SARA in grazing Irish cows from 14 herds, and found that 1 herd had a similar average $\mathrm{pH}(\mathrm{pH}=5.8)$ with other herds; however, the TVFA concentrations (77.87 $\mathrm{mmol} / \mathrm{L}$ ) were lower than other herds.

\section{Relationship Between Lactate and Thiamine Concentrations}

The negative relationship between thiamine concentrations and lactate contents in the rumen and blood was expected. A deficiency of thiamine during SARA inhibited pyruvate decarboxylation and caused the accumulation of pyruvate; subsequently, the enhanced lactate dehydrogenase activity increased lactate concentrations in rumen fluid (Wang et al., 2015) and blood (Kumar et al., 2015). In addition, SARA increased ruminal LPS (Penner et al., 2011) and increasing LPS might inhibit thiamine uptake (Zhu et al., 2015) in the rumen epithelium, thereby reducing thiamine in blood and increasing plasma lactate.

In the present study, the ruminal infusion of thiamine increased the concentrations of thiamine in the rumen and blood, and the lactate contents were decreased by thiamine infusion. Two reasons are possible for the inhibitory effects of thiamine on lactate. First, the accumulation of ruminal lactate is due to a greater abundance of lactate-producing bacterial species, Streptococcus bovis, as compared with lactate utilizers, M. elsdenii and S. ruminantium (Chaucheyras-Durand et al., 2008). Thiamine supplementation significantly reduced the population of $S$. bovis and increased the population of $M$. elsdenii (Wang et al., 2015), thus reducing the accumulation of lactate in the rumen. Second, higher thiamine concentrations in the rumen can support the protozoa population (Höltershinken et al., 2003); the increasing protozoa could store fermentable carbohydrates temporarily and consequently help to prevent a lot of lactate produced in a short time. The altered microbial metabolism by thiamine supplementation prevented the accumulation of ruminal lactate and eventually stabilized ruminal $\mathrm{pH}$. Hence, thiamine supplementation was assumed to be an effective strategy to attenuate SARA in our study.

\section{Effects of Thiamine Supplementation on Blood Metabolites}

Our study found that thiamine concentrations and the activity of $\alpha$-KGDHC in blood were increased by thiamine supplementation. The opposite was true for the lactate levels and the activity of lactate dehydrogenase. These results mentioned above were consistent with that of Falder et al. (2010), who found that thiamine supplementation increases serum thiamine and this increase is associated with a decrease in pyruvate and lactate levels in blood. The higher thiamine concentrations in blood may be due to the enhanced thiamine uptake. Thiamine uptake is mediated by thiamine transporter 1, 2 (THTR-1, THTR-2), and the gene expressions of THTR-1 and THTR-2 are inhibited by LPS and proinflammatory cytokines (TNF- $\alpha$, IL-6, IL-1 $\beta$; Zhu et al., 2015). Induction of SARA increased ruminal LPS and pro-inflammatory cytokines (Penner et al., 2011). Benfotiamine, a synthetic lipid-soluble derivative of thiamine, has been demonstrated to decrease the production of LPS, TNF- $\alpha$, and IL-6 and increases the anti-inflammatory cytokines IL-10 (Bozic et al., 2015). Based on the 3 facts above, we assumed that thiamine uptake may be impaired by increasing ruminal LPS and pro-inflammatory cytokines when SARA occurs, and thiamine supplementation may suppress the release of LPS and pro-inflammatory cytokines and consequently increase the uptake of thiamine. In addition, thiamine uptake by human cultured intestinal epithelial cells was found to be $\mathrm{pH}$ sensitive; thiamine uptake was reduced when $\mathrm{pH}$ deceased from 8 to 5 (Said et al., 1999). Thiamine supplementation tended to increase the ruminal $\mathrm{pH}$ in this study and that of Wang et al. (2015), and consequently increasing ruminal $\mathrm{pH}$ may promote the uptake of thiamine from the gastrointestinal tract to the blood. The increased thiamine contents in blood increased the activity of plasma PDH and $\alpha$-KGDHC in our study, the increasing enzyme activity promoted 
the amount of pyruvate flow to the TCA cycle and consequently reduced the conversion of pyruvate to lactate (Falder et al., 2010).

\section{CONCLUSIONS}

In the present study, the observed relationships between thiamine concentrations and $\mathrm{pH}$ (positive), acetate (positive) and lactate (negative), indicating that thiamine affect rumen fermentation and carbohydrate metabolism. We also found that thiamine deficiency occurred in dairy cows with SARA, ruminal infusion of thiamine $(180 \mathrm{mg} / \mathrm{kg}$ of DMI) could help attenuate the ruminal $\mathrm{pH}$ depression of SARA by improving the proportions of VFA and reducing lactate concentrations in rumen fluid and blood. Moreover, exogenous thiamine might enhance thiamine absorption by improving ruminal fermentation and alleviating inflammatory response. Furthermore, additional researches are needed to reveal how SARA affects thiamine uptake by gastrointestinal tract and the effects of thiamine on inflammation.

\section{ACKNOWLEDGMENTS}

The study was financially supported by the Project of National Nature Science Foundation of China (Grant No. 31572435), the National Sci-Tech Support Plan of China (2014BAD08B05), the Creative Workgroup on Dairy Industry of Beijing City 2012 (BJCYSTX-NY-1, China), and Importation and Development of HighCaliber Talents Project of Beijing Municipal Institutions (CIT\&TCD20130324, China). We also thank the University of Liège-Gembloux Agro-Bio Tech and more specifically the research platform Agriculture Is Life for the funding of the scientific stay in Belgium that made this paper possible.

\section{REFERENCES}

Analytical Methods Committee. 2000. Determination of thiamine and riboflavin in pet foods and animal feedingstuffs. Analyst (Lond.) 125:353-360.

AOAC. 1990. Official Methods of Analysis, 15th ed. AOAC, Washington, DC.

AOAC International. 1995. Official Methods of Analysis, 16th ed. AOAC International, Washington, DC.

Baldwin, R. L., W. Wood, and R. Emery. 1963. Conversion of glucose-C14 to propionate by the rumen microbiota. J. Bacteriol. 85:1346-1349.

Boyd, J. W., and J. R. Walton. 1977. Cerebrocortical necrosis in ruminants attempt to identify source of thiaminase in affected animals. J. Comp. Pathol. 87:581-589.

Bozic, I., D. Savic, D. Laketa, I. Bjelobaba, I. Milenkovic, S. Pekovic, N. Nedeljkovic, and I. Lavrnja. 2015. Benfotiamine attenuates inflammatory response in LPS stimulated BV-2 microglia. PLoS ONE 10:e0118372.

Brent, B. E. 1976. Relationship of acidosis to other feedlot animals. J. Anim. Sci. 43:930-935.
Brent, B. E., and E. E. Bartley. 1984. Thiamin and niacin in the rumen. J. Anim. Sci. 59:813-822.

Breves, G., M. Brandt, H. Hoeller, and K. Rohr. 1981. Flow of thiamin to the duodenum in dairy cows fed different rations. J. Agric. Sci. 96:587-591.

Bryant, M. P., and I. M. Robinson. 1961. Some nutritional requirements of the genus Ruminococcus. Appl. Microbiol. 9:91-95.

Bubber, P., Z. J. Ke, and G. E. Gibson. 2004. Tricarboxylic acid cycle enzymes following thiamine deficiency. Neurochem. Int. 45:10211028

Chaucheyras-Durand, F., N. D. Walker, and A. Bach. 2008. Effects of active dry yeasts on the rumen microbial ecosystem: Past, present and future. Anim. Feed Sci. Technol. 145:5-26.

Dabak, M., and Y. Gul. 2004. Thiamine deficiency in sheep with chronic rumen acidosis. Vet. Rec. 154:58-59.

Dunlop, R. H. 1998. Polioencephalomalacia (cerebrocortical necrosis) Pages 960-963 in Merck Veterinary Manual. S. E. Aiello, ed. Merck \& Co Inc., Philadelphia, PA.

Edwin, E., and R. Jackman. 1970. Thiaminase I in the development of cerebrocortical necrosis in sheep and cattle. Nature 228:772-774.

Falder, S., R. Silla, M. Phillips, S. Rea, R. Gurfinkel, E. Baur, A. Bartley, F. M. Wood, and M. W. Fear. 2010. Thiamine supplementation increases serum thiamine and reduces pyruvate and lactate levels in burn patients. Burns 36:261-269.

Friggens, N. C., J. D. Oldham, R. J. Dewhurst, and G. Horgan. 1998. Proportions of volatile fatty acids in relation to the chemical composition of feeds based on grass silage. J. Dairy Sci. 81:1331-1344.

Goiri, I., L. M. Oregui, and A. Garcia-Rodriguez. 2010. Use of chitosans to modulate ruminal fermentation of a 50:50 forage-to-concentrate diet in sheep. J. Anim. Sci. 88:749-755.

Gozho, G. N., D. O. Krause, and J. C. Plaizier. 2007. Ruminal lipopolysaccharide concentration and inflammatory response during grain-induced subacute ruminal acidosis in dairy cows. J. Dairy Sci. 90:856-866.

Hernández, J., J. L. Benedito, A. Abuelo, and C. Castillo. 2014. Ruminal acidosis in feedlot: From aetiology to prevention. Scientific World J. 702572.

Herrera-Saldana, R. E., J. T. Huber, and M. H. Poore. 1990. Dry matter, crude protein, and starch degradability of five cereal grains. J. Dairy Sci. 73:2386-2393.

Hill, J. H., C. G. Rammell, and S. Forbes. 1988. Blood thiamine levels in normal cattle and sheep at pasture. N. Z. Vet. J. 36:49-50.

Höltershinken, M., A. Höhling, G. Wendelken, K. Elias, and H. Scholz. 2003. Einflüsse auf den ruminalen Protozoenbesatz des Rindes (in vitro) Teil 2: Wirkung einer subklinischen Pansenazidose ohne und mit Thiaminsubstitution. Tierärztliche Praxis Großtiere. 31:178182.

Hu, W. L., J. X. Liu, J. A. Ye, Y. M. Wu, and Y. Q. Guo. 2005. Effect of tea saponin on rumen fermentation in vitro. Anim. Feed Sci. Technol. 120:333-339.

Jia, Y. M., R. H. Cong, R. S. Li, X. J. Yang, Q. W. Sun, N. Parvizi, and R. Q. Zhao. 2012. Maternal low-protein diet induces genderdependent changes in epigenetic regulation of the glucose-6-phosphatase gene in newborn piglet liver. J. Nutr. 142:1659-1665.

Kanehisa, M., and S. Goto. 2000. KEGG: Kyoto encyclopedia of genes and genomes. Nucleic Acids Res. 28:27-30.

Karapinar, T., M. Dabak, and O. Kizil. 2010. Thiamine status of feedlot cattle fed a high-concentrate diet. Can. Vet. J. 51:1251-1253.

Karapinar, T., M. Dabak, O. Kizil, and E. Balikci. 2008. Severe thiamine deficiency in sheep with acute ruminal lactic acidosis. J. Vet. Intern. Med. 22:662-665.

Khafipour, E., D. O. Krause, and J. C. Plaizier. 2009. A grain-based subacute ruminal acidosis challenge causes translocation of lipopolysaccharide and triggers inflammation. J. Dairy Sci. 92:10601070.

Krause, K. M., and G. R. Oetzel. 2005. Inducing subacute ruminal acidosis in lactating dairy cows. J. Dairy Sci. 88:3633-3639.

Kumar, K. N., V. R. Shah, B. K. Parikh, and S. Sonde. 2015. Reversal of severe lactic acidosis with thiamine in a renal allograft recipient. Indian J. Crit. Care Med. 19:425-428. 
Li, S., E. Khafipour, D. Krause, A. Kroeker, J. Rodriguez-Lecompte, G. Gozho, and J. Plaizier. 2012. Effects of subacute ruminal acidosis challenges on fermentation and endotoxins in the rumen and hindgut of dairy cows. J. Dairy Sci. 95:294-303.

Macfarlane, S., and G. T. Macfarlane. 2003. Regulation of short-chain fatty acid production. Proc. Nutr. Soc. 62:67-72.

Mao, S. Y., W. J. Huo, and W. Y. Zhu. 2016. Microbiome-metabolome analysis reveals unhealthy alterations in the composition and metabolism of ruminal microbiota with increasing dietary grain in a goat model. Environ. Microbiol. 18:525-541.

Miller, B., J. Meiske, and R. Goodrich. 1986. Effects of grain source and concentrate level on B-vitamin production and absorption in steers. J. Anim. Sci. 62:473-483.

Nagaraja, T. G., and K. F. Lechtenberg. 2007. Acidosis in feedlot cattle. Vet. Clin. North Am. Food Anim. Pract. 23:333-350.

NRC. 2001. Nutrient Requirements of Dairy Cattle. 7th rev. ed. Natl. Acad. Press, Washington, DC.

O'Grady, L., M. L. Doherty, and F. J. Mulligan. 2008. Subacute ruminal acidosis (SARA) in grazing Irish dairy cows. Vet. J. 176:44-49.

Penner, G., K. Beauchemin, and T. Mutsvangwa. 2007. Severity of ruminal acidosis in primiparous Holstein cows during the periparturient period. J. Dairy Sci. 90:365-375.

Penner, G. B., M. A. Steele, J. R. Aschenbach, and B. W. McBride. 2011. Ruminant Nutrition Symposium: Molecular adaptation of ruminal epithelia to highly fermentable diets. J. Anim. Sci. 89:1108-1119.

Randhawa, S., A. Ahuja, and S. Rathor. 1988. Effect of lactic-acidosis on histamine and thiamine levels in buffalo calves. Indian J. Anim. Sci. 58:1019-1023.

Said, H. M., A. Ortiz, C. K. Kumar, N. Chatterjee, P. K. Dudeja, and S. Rubin. 1999. Transport of thiamine in human intestine: Mechanism and regulation in intestinal epithelial cell model Caco-2. Am. J. Physiol. 277:C645-C651.

Schlau, N., L. L. Guan, and M. Oba. 2012. The relationship between rumen acidosis resistance and expression of genes involved in regulation of intracellular $\mathrm{pH}$ and butyrate metabolism of ruminal epithelial cells in steers. J. Dairy Sci. 95:5866-5875.

Schwab, E., C. Schwab, R. Shaver, C. Girard, D. Putnam, and N. Whitehouse. 2006. Dietary forage and nonfiber carbohydrate contents influence B-vitamin intake, duodenal flow, and apparent ruminal synthesis in lactating dairy cows. J. Dairy Sci. 89:174-187.
Silverman, M., and C. H. Werkman. 1939. Adaptation of the propionic-acid bacteria to vitamin $\mathrm{B}_{1}$ synthesis including a method of assay. J. Bacteriol. 38:25-32.

Steinberg. W., and W. Kaufmann. 1977. Untersuchungen zur bakteriellen Thiaminsynthese in den Vormägen von Milchkühen. Zeitschrift für Tierphysiologie Tierernährung und Futtermittelkunde 39:289-301.

Tafaj, M., M. Schollenberger, J. Feofilowa, Q. Zebeli, H. Steingass, and W. Drochner. 2006. Relationship between thiamine concentration and fermentation patterns in the rumen fluid of dairy cows fed with graded concentrate levels. J. Anim. Physiol. 90:335-343.

Van Soest, P. J., J. B. Robertson, and B. A. Lewis. 1991. Methods for dietary fiber, neutral detergent fiber, and nonstarch polysaccharides in relation to animal nutrition. J. Dairy Sci. 74:3583-3597.

Wang, H., X. Pan, C. Wang, M. Wang, and L. Yu. 2015. Effects of different dietary concentrate to forage ratio and thiamine supplementation on the rumen fermentation and ruminal bacterial community in dairy cows. Anim. Prod. 55:189-193.

Yahaghi, M., J. B. Liang, J. Balcells, R. Valizadeh, A. R. Alimon, and Y. W. Ho. 2012. Effect of replacing barley with corn or sorghum grain on rumen fermentation characteristics and performance of Iranian Baluchi lamb fed high concentrate rations. Anim. Prod. $52: 263-268$.

Yamane, K., I. L. Indalao, J. Chida, Y. Yamamoto, M. Hanawa, and H. Kido. 2014. Diisopropylamine dichloroacetate, a novel pyruvate dehydrogenase kinase 4 inhibitor, as a potential therapeutic agent for metabolic disorders and multiorgan failure in severe influenza. PLOS ONE 9:e98032.

Zhang, J., M. Z. Wang, Z. M. Hao, L. H. Yu, and H. R. Wang. 2014. Effects of thiamine on concentrations of volatile fatty acids and lactate in culture medium of high concentrate substrate after in vitro rumen fermentation. Chinese J. Anim. Nutr. 26:489-495.

Zhu, E., L. Fang, V. Subramanian, H. Said, and C. Sassoon. 2015. Lipopolysaccharide and cytokines inhibit thiamine uptake and thiamine transporter gene expression in C2c12 myoblasts. Am. J. Respir. Crit. Care Med. 191:4361. (Abstr.)

Zinn, R. A., F. Owens, R. Stuart, J. Dunbar, and B. Norman. 1987. B-vitamin supplementation of diets for feedlot calves. J. Anim. Sci. 65:267-277. 